\title{
A prospective randomized high fidelity simulation center based side-by-side comparison analyzing the success and ease of conventional versus new generation video laryngoscope technology by inexperienced laryngoscopists
}

THOMAS C. WASS $(\triangle)$ Mayo Clinic 200 First Street Rochester, MN 55901 Phone: (507) 255-1612

Fax: (507) 255-6463 E-mail: wass.thomas@mayo.edu

THOMAS C. WASS • ADAM K. JACOB • SANDRA L. KOPP • LAURENCE C. TORSHER

Department of Anesthesiology College of Medicine Mayo Clinic, Rochester, MN 55905

\author{
THOMAS C. WASS • ADAM K. JACOB • SANDRA L. KOPP • \\ LAURENCE C. TORSHER
}

\begin{abstract}
Introduction. Indirect video laryngoscopes are altering the landscape of airway management. The primary aim of this prospective randomized patient simulator analysis was to objectively compare video laryngoscopes to standard airway management techniques in novice users.

Methods. "First year medical students were exposed to high-fidelity simulated normal and difficult airway scenarios while using an array of indirect video laryngoscopes (e.g., the GlideScope, McGRATH or Pentax AWS-100) that were compared to Macintosh laryngoscope and fiberoptic bronchoscope (i.e., historic gold standards for normal and difficult airways, respectively)." Results. In the normal airway scenario, the best glottic view (both subjective and objective) was obtained with the video laryngoscopes and intubation success rates were highest with the video laryngoscopes (100\% success rate for each device) and Macintosh (80\%). In the difficult airway scenario, the best glottic view was achieved with all video laryngoscopes and the fiberoptic bronchoscope; however, tracheal intubation was best achieved with the video laryngoscopes (100\% success rate for each device) whereas the success rate with the bronchoscope was only $36 \%$.

Discussion. Our findings support the use of the GlideScope, McGRATH, or Macintosh laryngoscopes for novice users managing a normal airway. When managing the difficult airway, there was no difference between any video or Macintosh laryngoscope in the time to successfully intubate the trachea. Over time, study participants demonstrated learned behavior as they became more facile with all devices. When comparing the video laryngoscopes, all three performed similarly overall and proved useful in the hands of novice users. Regardless of airway difficulty, the fiberoptic bronchoscope yielded the worst results.
\end{abstract}

Key words: airway, airway management, airway equipment, patient simulation, success, tracheal intubation

\section{Introduction}

Endotracheal intubation may be chall- enging, particularly for health care providers less adept at direct laryngoscopy, (e.g. medical support, emergency medical technicians, medical students, novice anesthesia residents or nurse anesthesia students). Previous inve- stigators have reported intubation success rates of a mere 35 to $65 \%$ in the hands of inexperienced users and direct laryngoscopic competency requires at least 50 tracheal intubations. (1-4) latrogenic airway trauma, failed 
tracheal intubations, or unrecognized esophageal intubations are causative factors that may contribute to patient morbidity and mortality in the field or during hospitalization. Thus, regardless of indication (elective or emergent), the evidence does not support safe tracheal intubation by inexperienced laryngoscopists.

At the turn of the present millennium, medical equipment manufacturers began research, development, and production of an array of indirect video laryngoscopes (e.g. the GlideScope, McGRATH or Pentax) with inherent design attributes. Use of these laryngoscopes may result in improved patient safety when compared to conventional airway management equipment; however, side-by-side comparative data assessing quality of glottic view and intubation success rates are scarce in the medical literature. The primary goal of this prospective randomized (of device sequence) investigation was to test the hypotheses that inexperienced laryngoscopists will:

1. have a higher success rate of tracheal intubation, shorter setup time, shorter time to intubation, fewer intubation attempts, and less dental compression using an indirect video laryngoscope (the GlideScope, the McGRATH scope or the Pentax AWS-100) compared to conventional techniques (i.e., direct laryngoscopy or intubation with a fiberoptic bronchoscope). It deserves mention that the latter two devices were selected, as they are representative of historic gold standard medical equipment typically employed when managing normal and difficult airways, respectively.

2. prefer using an indirect video laryngoscope for tracheal intubation when compared to conventional techniques.

\section{Materials and Methods}

Recruitment of participants

Following Mayo Clinic Institutional Review Board approval, first year medical students currently enrolled at Mayo Clinic College of Medicine in Rochester, MN were recruited for participation by e-mail correspondence. Students were excluded if they had previously performed five or more tracheal intubations, were legally blind, or had impaired use of both upper extremities (defined as having hemiplegia, quadriplegia, or other musculoskeletal disorder that would preclude normal daily activity).

\section{Simulation Center and Laryngoscopic} Equipment

At the Mayo Clinic Multidisciplinary Simulation Center, participants were given a five to ten minute tutorial by a company representative on how to correctly use the McGRATH ${ }^{\circledR}$ (Series 5, LMA Corporation-Aircraft Medical, Edinburgh, UK), Pentax AWS-100 (Pentax Corporation, Montvale, NJ), GlideScope ${ }^{\circledR}$ (GVL, Verathon, Bothell, WA), Macintosh (\#3 Fiber Optics Blade, Herrsching, German) and Olympus fiberoptic scope (LF-DP 3.2, Hamburg, Germany). In all cases, a 7.5 cuffed endotracheal tube was used. Where appropriate (i.e. when using the Macintosh, McGRATH, and GlideScope), the GlideRite ${ }^{\circledR}$ Rigid Stylet (Verathon, Bothell, WA) was used to facilitate tracheal intubation. This was done to eliminate equipment bias that may have resulted from variability associated with dynamic metallurgic properties of a standard aluminum stylet over time. Thereafter, a brief in-service was provided on the Learadal mannequin (SimMan Patient Simulator, Laerdal Medical Corporation, Wappingers Falls, NY). Via closed envelope randomization, participants started with one of the above-mentioned laryngoscopes and proceeded with the other devices in a predetermined randomized order on the same mannequin. Participants were allowed three minutes to complete each of two separate airway scenarios with each of the pieces of airway equipment. The first scenario simulated a normal airway while the second simulated a difficult airway using hypopharyngeal bladder inflation.

\section{End-point evaluation}

Using the Device Evaluation Survey instrument (appendix 1), each participant was evaluated by an independent observer who assessed: 1) tracheal intubation success, 2) best glottic view obtained (using the previously described Cormack Lehane grading system), $(5,6) 3)$ number of attempts required to successfully intubate the trachea, 4) time(s) required to set up the device plus obtain a glottic view and intubate the trachea, and 5) severity of dental compression during intubation attempt for each piece of airway equipment during both the normal and difficult intubation scenarios. A 180 second time limit was placed on each scenario. If unsuccessful in completing any of these tasks within three minutes, this was recorded and considered a failed attempt. After completing all 10 airway scenarios (five devices used for two airway scenarios), each participant anonymously (i.e., no medical student identifiers on the questionnaire) completed a six-question Post Evaluation Survey (appendix 2).

\section{Data Analysis}

Data was analyzed as paired comparisons between devices. Paired comparisons of continuous data were analyzed using the Wilcoxan Rank Sum Test. Paired comparisons of qualitative binary and ordinal data were analyzed using McNemar's Test. In the case of 3-level ordinal data, data in categories "1" and "2" were grouped and compared to data in category "3" (e.g. "poor" + "good" vs. "outstanding"). In the case of glottic view, data in categories "1" and "2" were grouped and compared to data grouped from categories "3", "4", and "not visualized." Statistical significance was assumed at $p=0.005$ after adjusting for multiple comparisons using the Bonferroni correction. Sample size estimate was based on the primary outcome of the proportion of successful intubations. Based on a literature review, we assumed 95\% success with the use of a video laryngoscope compared to $60 \%$ success with the use of Macintosh. Assuming a type I error rate of $5 \%$ and power of 80\%, 22 medical student recruits were required for participation.

\section{Results}

A total of 25 first year Mayo Clinic 
medical students (13 male, 12 female) participated in the comparison study. Summaries of airway device evaluation data for normal and difficult airway scenarios are presented in table 1 and table 2 , respectively. The summary of comparisons presented in table 3 is those that met statistical significance after Bonferroni correction.

\section{Normal Airway Scenario}

Ease of device assembly as assessed by the evaluator was significantly worse for the Pentax when compared to the Macintosh ( $p=0.0001)$, GlideScope ( $p$ $=0.0001)$, McGRATH $(p=0.0002)$, and fiberoptic bronchoscope ( $p=0.003)$. The ability to obtain a glottic view was significantly worse for Macintosh when compared to the McGRATH, GlideSco$p e$, and Pentax ( $p=0.001$ for each). Similarly, ability to obtain a glottic view proved more challenging for students using the fiberoptic bronchoscope than the McGRATH, GlideScope, and Pen$\operatorname{tax}(p=0.0002$ for each). The ability to intubate the trachea was significantly worse for the fiberoptic bronchoscope when compared to the Macintosh $(p=0.002)$, GlideScope $(p=0.005)$, McGRATH ( $p=0.0001)$, and Pentax ( $p$ $=0.0001)$. The Pentax fared better than the Macintosh $(p=0.002)$ and Glidescope ( $p=0.0001$ ), but no significant difference was observed between the Pentax and McGRATH. The severity of dental compression was significantly less with the fiberoptic bronchoscope compared to all other devices ( $p=$ 0.0001 ). The best glottic view obtained using the Macintosh laryngoscope was significantly worse than the view achieved with the Pentax ( $p=0.005)$, McGRATH ( $p=0.0001)$, GlideScope $(p=0.0001)$, and fiberoptic bronchoscope $(p=0.0001)$. Specifically, the fraction of our participants reporting a Grade 1 glottic view was: Macintosh $12 \%$, fiberoptic bronchoscope $52 \%$, McGRATH 88\%, GlideScope 88\%, and Pentax 96\%. No significant difference was noted among the three video laryngoscopes. Eleven of 25 medical students (44\%) reported, "Glottis not visualized" when using the fiberoptic bronchoscope, whereas a glimpse of the glottis was achieved with all of the other devices. A grade 3 or 4 view was reported $36 \%$ of the time with the Macintosh. The number attempts required to obtain the best glottic view was greater with the fiberoptic bronchoscope than the Pentax ( $p=0.0003)$, GlideScope $(<0.0001)$, or McGRATH $(p=0.0009)$. The time to assemble the device and obtain the best glottic view was significantly longer for the fiberoptic bronchoscope (median time 146 seconds) when compared to the Macintosh (45 seconds, $p=0.0001$ ), McGRATH (29 seconds, $p=0.0001$ ), GlideScope (32 seconds, $p=0.0001$ ), and Pentax (75 seconds, $p=0.0001$ ). In regard to the video laryngoscopes, the time to obtain the best glottic view was significantly shorter with the GlideScope $(p=0.0002)$ or McGRATH ( $p$ $=0.0004)$ than the Pentax. Success of tracheal intubation was significantly worse for the fiberoptic bronchoscope when compared to all other devices ( $p$ $<0.0001$ for each). Specifically, 100\% success was observed for all video laryngoscopes, but only $80 \%$ and $16 \%$ for the Macintosh and fiberoptic bronchoscope, respectively. That is, timelimited intubation failures (i.e. tracheal intubations exceeding the 180 second time limit provided to successfully complete the task) were observed in 21 of 25 (84\%) fiberoptic and 5 of 25 (20\%) of Macintosh intubations. After excluding study participants who failed to successfully intubate the trachea, there were no statistically significant differences in the number of attempts to intubate the trachea. The time to successfully intubate the trachea was significantly worse for the fiberoptic bronchoscope (Median time 138 seconds) versus all other devices ( $p \leq 0.0002$ for each). In regard to the video laryngoscopes, intubating the trachea was significantly longer with the Pentax (84 seconds) versus GlideScope (50 seconds, $p=$ 0.0002 ) and McGRATH (45 seconds, $p$ $=0.0004$ ).

\section{Difficult Airway Scenario}

In contrast to the normal airway sce- nario, there were no statistically significant differences among devices with regard to ease of device assembly (learned behavior, see Discussion). The ability to obtain a glottic view was significantly worse for the Macintosh when compared to the McGRATH ( $p=$ 0.004), GlideScope ( $p=0.0002)$, and Pentax $(p=0.001)$. Similarly, ability to obtain a glottic view was significantly worse for the fiberoptic bronchoscope when compared to the McGRATH ( $p=$ 0.005), GlideScope ( $p=0.0002)$, and Pentax $(p=0.001)$.

The ability to intubate the trachea was significantly worse for the fiberoptic bronchoscope compared to the Macintosh $(p=0.005)$, McGRATH ( $p=$ $0.001)$, GlideScope $(p=0.0001)$, and Pentax $(p=0.0001)$. Additionally, the Pentax achieved better results than the Macintosh $(p=0.002)$. The severity of dental compression was significantly less with the fiberoptic bronchoscope versus all other devices ( $p<0.0001$ for each). The best glottic view obtained using the Macintosh was significantly worse than that visualized with the McGRATH ( $p=0.001)$, GlideScope ( $p=0.003$ ), or fiberoptic bronchoscope $(p=0.0002)$. Specifically, the fraction of our participants reporting a Grade 1 glottic view was: Macintosh 8\%, GlideScope 52\%, Pentax 52\%, McGRATH 60\%, and fiberoptic bronchoscope $72 \%$. A Grade 3 or 4 view was reported in 64\% Macintosh, 4\% McGRATH, 4\% GlideScope, and 0\% Pentax and Fiberoptic bronchoscope. Eight percent and $20 \%$ of our medical student reported "Glottis not visualized" when using the Macintosh or fiberoptic bronchoscope, respectively. There were no statistically significant differences in the number of attempts required to obtain the best glottic view.

The time to assemble the device and obtain the best glottic view was significantly worse with the fiberoptic bronchoscope (Median time 101 seconds) when compared to the Pentax (38 seconds, $p=0.0001$ ), Macintosh (30 seconds, $p=0.001)$, McGRATH (25 seconds, $p=0.0001$ ), or GlideScope (23 seconds, $p=0.002$ ). In regard to 
the video laryngoscopes, the time to assemble the device and obtain the best glottic view was significantly worse for the Pentax (38 seconds) when compared to the McGRATH (25 seconds, $p$ $=0.0003$ ) and GlideScope (23 secon$d s, p=0.0001$ ). Success of tracheal intubation was significantly worse for the fiberoptic bronchoscope when compared to all other devices ( $p=0.0001$ for each). Specifically, $100 \%$ success was observed for the video laryngoscopes, but only 23 of 25 (92\%) and 9 of 25 (36\%) for the Macintosh and fiberoptic bronchoscope, respectively. That is, in 8\% (Macintosh) and 64\% (fiberoptic bronchoscope) of the attempts, medical students participating in this study were unable to intubate the trachea within the predetermined 3 minute time cutoff thereby constituting a failed intubation. After pairwise comparisons of study participants who successfully intubated the trachea, there were no statistically significant differences in the number of attempts to intubate the trachea. The time to intubate the trachea was significantly longer for the fiberoptic bronchoscope (median time 104 seconds) when compared to the Pentax (43 seconds, $p=0.003$ ), GlideScope (38 seconds, $p=0.003$ ), Macintosh (34 seconds, $p<0.0001$ ), and McGRATH (53 seconds, $p<0.00001)$. However, it deserves reiteration that time-limited intubation failures were observed in $64 \%$ of fiberoptic and $8 \%$ of Macintosh intubations. Thus, the intubation times may have been even worse for these two devices if we had allowed the clock to keep ticking rather than capping with a time-based limitation of 180 seconds. Looking at these data from a different perspective, once the vocal cords were visualized, the median time to intubate the trachea was significantly longer for the fiberoptic bronchoscope (55 seconds) when compared to the Pentax (5 seconds, $p<0.0001$ ), Macintosh (6 seconds, $p<0.0001$ ), and the GlideScope (11 seconds, $p=0.003$ ). Similarly, the median time to intubate the trachea was significantly longer for the McGRATH (18 seconds) when compared to the Pentax $(p<0.0001)$ and Macintosh $(p=0.0006)$ and also when the GlideScope was compared to Pentax $(p<0.0001)$.

\section{Post-Evaluation Survey}

Results of the post-evaluation survey are summarized in table 4 . The majority (44\%) of participants felt the Macintosh laryngoscope was the easiest device to set-up (assemble) followed by the McGRATH 28\%, GlideScope 24\%, fiberoptic bronchoscope $4 \%$, and Pentax $0 \%$. In contrast, when queried as to which device they thought was the most difficult to assemble, $56 \%$ of the respondents believed that the Pentax posed the greatest challenge. In regard to user-friendliness, most of participants (40\%) reported the McGRATH laryngoscope was the easiest device to use while the majority (88\%) cited the fiberoptic bronchoscope as being the most difficult device to manage. When questioned "which device would you choose to intubate the trachea of a patient with a normal appearing airway", our participants selected the McGRATH 36\%, Pentax $32 \%$, Macintosh 20\%, GlideScope 12\% and the fiberoptic bronchoscope $0 \%$ of the time. However, when faced with a difficult appearing airway, most participants (44\%) chose the Pentax, while $32 \%$ selected the McGRATH, 16\% the GlideScope, and none would opt for the Macintosh laryngoscope.

\section{Discussion}

The present study was a prospective randomized high-fidelity simulation based side-by-side comparison of a wide array of indirect video laryngoscopes with the Macintosh laryngoscope and fiberoptic bronchoscope (i.e. typical historic gold standards for normal and difficult airways, respectively) in the hands of inexperienced users. Our study is unique in that we made these comparisons over a broader (relative to previous comparative studies) spectrum of laryngoscopic equipment in both normal and difficult airway settings.

In brief, we observed inexperienced laryngoscopists were better able to intubate the trachea in a timely manner with the video laryngoscopes when compared to the fiberoptic bronchoscope and Macintosh in both airway scenarios.

More specifically, in the normal airway scenario, we observed the best glottic view (both subjective and objective) was obtained with the video laryngoscopes whereas intubation success rates were highest with the video laryngoscopes (100\% success rate for each device) and Macintosh (80\%). In the difficult airway scenario, the best glottic view was achieved with all of the video laryngoscopes and the fiberoptic bronchoscope; however, tracheal intubation was best achieved with the video (100\% success rate for each device) and Macintosh (92\% success rate) laryngoscopes. Regardless of the level of airway difficulty, the fiberoptic bronchoscope yielded the worst results. Most importantly, intubation success rate and time to intubation were substantially worse with the bronchoscope compared to all other devices. In regard to which one of the video laryngoscopes proved superior, the time taken to assemble the Pentax adversely contributed to the elapsed time required to obtain best glottic view and time to intubate thereby detracting from its' attractiveness in the normal airway scenario. However, this was not the case in the difficult airway setting. That is, timed events with the Pentax were similar to the other video devices. We envision this resulted from our participants becoming increasingly facile (i.e. through learned behavior) with Pentax assembly with subsequent use. Thus, by time they were exposed to the difficult airway scenario, they had mastered the assembly process and had overcome this time-based limitation. Taken together, all three video laryngoscopes performed similarly overall and proved useful when used by novice health care providers.

Medical personnel who perform infrequent tracheal intubation bear a high-risk of failure when encountering patients with a normal or challenging airway. Tracheal intubation success rates in health care providers who are less familiar with direct laryngoscopy (e.g. medical support staff, emergency medical 
technicians, medical students, code teams, novice anesthesia residents) range from 35 to $65 \%$. $(1,2)$ New generation indirect video laryngoscopes may improve these statistics, potentially improving patient safety. Video technology appears to be more "user friendly" across a broader spectrum of clinical abilities. For example, the learning curve to achieve $\geq 90 \%$ success with Macintosh or Miller laryngoscopes requires 47 to 57 intubations, whereas only five attempts are necessary with a video laryngoscope. $(3,4)$ Performing 50 tracheal intubations is difficult to achieve for most non-anesthesia healthcare providers and once competency is attained, the clinician's technical skiIls may deteriorate over time if competency is not maintained. (2) Considering mastery is achieved with one tenth the number of intubations when using a video laryngoscope, it may be a more attainable goal for maintaining longterm competency in providers doing infrequent intubations.

The most common complaint when using video laryngoscopes was inability to negotiate the ETT into the trachea despite a Cormack and Lehane grade 1 or 2 view. (7-10) Such a complaint resulted in the development of the GlideRite ${ }^{\circledR}$ Rigid Stylet (Verathon, Bothell, WA). In our clinical practice (in both experienced and inexperienced anesthesia care team members), this stylet has by-and-large obviated this inherent shortcoming.

Previous investigations have not compared the historic gold standard (i.e. the fiberoptic bronchoscope) to indirect video laryngoscopes. In the present study, we overcome this limitation by comparing curved blade direct laryngoscope (Macintosh) to curved blade indirect video laryngoscopes (GlideScope ${ }^{\circ}$, McGRATH, Pentax) and the flexible fiberoptic bronchoscope. There is ample evidence that fiberoptic bronchoscopy in anesthesia practice is extremely useful for management of suspected or known difficult airways, but requires significant expertise and skill to perform. $(11,12)$ The American Society of Anesthesiologists Airway
Practice Guidelines group reported overall success rates of 87 to $100 \%$ with fiberoptic-guided intubation in difficult airways, with a success rate of 75 to $80 \%$ on first attempt, a mean number of 1.2 attempts, and a mean time to intubation that may exceed 400 seconds. (11) Although fiberoptic intubation has a high success rate, it may come at the expense of time required to safely secure the airway and a steeper learning curve. In our study, time-limited intubation failures clearly detracted from the clinical usefulness of the fiberoptic bronchoscope when used by inexperienced health care providers.

In the difficult airway scenario, the best glottic views were achieved with the video laryngoscopes and fiberoptic bronchoscope. It took substantially longer and a greater number of attempts with the fiberoptic bronchoscope to obtain the "best glottic view." However, in defense of the bronchoscope, dental compression was negligible with the bronchoscope, which was in stark contrast to other devices (especially the Macintosh). Despite the great glottic view, the success of tracheal intubation was only $36 \%$ with the bronchoscope. In contrast, 100\% and $92 \%$ intubation success rates were observed with the video laryngoscopes and Macintosh, respectively.

In clinical situations when an unanticipated difficult tracheal airway is encountered, intubation time includes the time required for the physical act of placing the endotracheal tube as well as that required for set-up of the equipment chosen. In the earlier studies, an inherent limitation was omission of assembly time. In our study, we assumed time to secure the airway includes set-up plus the actual time required to intubate the trachea.

In the difficult airway scenario, we made an interesting observation. Specifically, despite increased complexity of airway difficulty encountered in the latter scenarios, we report no significant difference between any of the video devices or Macintosh laryngoscope in the time to successfully intubate the trachea. This observation is seemingly counterintuitive, as the video laryngoscopes provide a clear advantage over the Macintosh (in regard to glottic view and ease of tracheal intubation) in the clinical setting of difficult tracheal intubation. We envision the high success rate of the Macintosh resulted from learned behavior, as study participants became more adept with all devices over time (i.e. as they sequentially progressed from the normal to difficult airway scenarios) and dental compression was of little concern (i.e. they were able to apply a great deal of force on the mannequin's upper central incisors without apparent repercussion) to these inexperienced users. Additionally, when comparing the three video laryngoscopes, this learned behavior became evident as the time to assemble the Pentax plus intubate the trachea became shorter (see above). Thus, what appeared to be a shortcoming of the device in the normal airway scenario, disappeared over time as the participants became more familiar with the device. Such an observation is a potential study limitation. That is, although all subjects enrolled in this study had minimal or no exposure to laryngoscopy prior to the investigation, we anticipated each study subject would become more facile with laryngoscopy while progressing through the study sequence. Our data shows that this was likely the case, as the time to intubate actually decreased as the students made the transition from the normal to difficult airway scenario. Additionally, the rate of intubation success improved over time with the Macintosh and fiberoptic bronchoscope despite an increase in the level of airway complexity. Thus, it is conceivable this innate learning process biased our data toward a favorable outcome when comparing the normal and difficult scenarios. However, since all participants were randomized to the starting device and progression through the devices order, we anticipate inter-laryngoscope bias evened out across all stations for all participants.

Another study limitation pertains to realistically emulating various airway scenarios is difficult when using mannequin simulation. For example, 
airway models are devoid of secretions and blood, which would tend to bias the data in favor of a good result (e.g. successful tracheal intubation). However, providing such reproducibility afforded by an airway model would be impossible if using real patients.

In summary, our findings support the use of the GlideScope, McGRATH, or Macintosh laryngoscopes for novice users managing a normal airway. When managing the difficult airway, there was no difference between any video or Macintosh laryngoscope in the time to successfully intubate the trachea. Regardless of airway difficulty, the fibe- roptic bronchoscope yielded the worst results in these novice users. Over time, study participants demonstrated learned behavior as they became more facile with all devices. When comparing the video laryngoscopes, all three performed similarly overall and proved useful in the hands of novice users.

Table 1. Summary of device comparisons during a simulated normal airway.

\begin{tabular}{|c|c|c|c|c|c|}
\hline Characteristic & $\begin{array}{l}\text { Maclntosh } \\
\text { Laryngoscope } \\
n=25\end{array}$ & $\begin{array}{l}\text { McGRATH® } \\
\text { Series } 5 \text { Video } \\
\text { Laryngoscope } \\
n=25\end{array}$ & $\begin{array}{l}\text { GlideScope }{ }^{\circledR} \\
\text { Video Laryngos- } \\
\text { cope } \\
\mathrm{n}=25\end{array}$ & $\begin{array}{l}\text { Pentax AWS- } \\
\text { S100 Video } \\
\text { Laryngoscope } \\
n=25\end{array}$ & $\begin{array}{l}\text { Fiberoptic Bron- } \\
\text { choscope } \\
n=25\end{array}$ \\
\hline $\begin{array}{l}\text { Ability to assemble the } \\
\text { device } \\
\text { Outstanding } \\
\text { Good } \\
\text { Poor }\end{array}$ & $\begin{array}{l}24 \\
1 \\
0\end{array}$ & $\begin{array}{l}22 \\
3 \\
0\end{array}$ & $\begin{array}{l}23 \\
1 \\
1\end{array}$ & $\begin{array}{l}6 \\
14 \\
5\end{array}$ & $\begin{array}{l}18 \\
6 \\
1\end{array}$ \\
\hline $\begin{array}{l}\text { Ability to obtain glottic view } \\
\text { Outstanding } \\
\text { Good } \\
\text { Poor }\end{array}$ & $\begin{array}{l}9 \\
11 \\
5\end{array}$ & $\begin{array}{l}21 \\
4 \\
0\end{array}$ & $\begin{array}{l}21 \\
4 \\
0\end{array}$ & $\begin{array}{l}20 \\
4 \\
1\end{array}$ & $\begin{array}{l}4 \\
9 \\
12\end{array}$ \\
\hline $\begin{array}{l}\text { Ability to intubate the tra- } \\
\text { chea } \\
\text { Outstanding } \\
\text { Good } \\
\text { Poor }\end{array}$ & $\begin{array}{l}13 \\
7 \\
5\end{array}$ & $\begin{array}{l}21 \\
4 \\
0\end{array}$ & $\begin{array}{l}16 \\
9 \\
0\end{array}$ & $\begin{array}{l}24 \\
1 \\
0\end{array}$ & $\begin{array}{l}1 \\
3 \\
21\end{array}$ \\
\hline $\begin{array}{l}\text { Severity of dental compre- } \\
\text { ssion } \\
\text { None } \\
\text { Moderate } \\
\text { Severe }\end{array}$ & $\begin{array}{l}1 \\
7 \\
17\end{array}$ & $\begin{array}{l}2 \\
19 \\
4\end{array}$ & $\begin{array}{l}1 \\
21 \\
3\end{array}$ & $\begin{array}{l}2 \\
18 \\
5\end{array}$ & $\begin{array}{l}24 \\
1 \\
0\end{array}$ \\
\hline $\begin{array}{l}\text { Best glottic view } \\
1 \\
2 \\
3 \\
4 \\
\text { Glottis not visualized }\end{array}$ & $\begin{array}{l}3 \\
11 \\
7 \\
2 \\
2\end{array}$ & $\begin{array}{l}22 \\
3 \\
0 \\
0 \\
0\end{array}$ & $\begin{array}{l}22 \\
3 \\
0 \\
0 \\
0\end{array}$ & $\begin{array}{l}24 \\
1 \\
0 \\
0 \\
0\end{array}$ & $\begin{array}{l}13 \\
1 \\
0 \\
0 \\
11\end{array}$ \\
\hline $\begin{array}{l}\text { Attempts to obtain best } \\
\text { glottic view } \\
1 \\
2 \\
3+\end{array}$ & $\begin{array}{l}12 \\
4 \\
9\end{array}$ & $\begin{array}{l}19 \\
4 \\
2\end{array}$ & $\begin{array}{l}23 \\
2 \\
0\end{array}$ & $\begin{array}{l}19 \\
5 \\
1\end{array}$ & $\begin{array}{l}3 \\
7 \\
15\end{array}$ \\
\hline $\begin{array}{l}\text { Median time (sec) to assem- } \\
\text { ble the device and obtain } \\
\text { best glottic view }\left(25^{\text {th }}, 75^{\text {th }}\right)\end{array}$ & $45(23,127)$ & $29(22,52)$ & $32(24,48)$ & $75(38,108)$ & $146(86,180)$ \\
\hline $\begin{array}{l}\text { Success of tracheal intu- } \\
\text { bation }\end{array}$ & 20 & 25 & 25 & 25 & 4 \\
\hline $\begin{array}{l}\text { Median time to assemble the } \\
\text { device and intubate the tra- } \\
\text { chea* }\left(25^{\text {th }}, 75^{\text {th }}\right)\end{array}$ & $46(32,90)$ & $45(35,87)$ & $50(38,83)$ & $84(44,117)$ & $138(91,166)$ \\
\hline
\end{tabular}

* Median time based on subjects that attempted tracheal intubation (Macintosh $=20$, Fiberoptic $=4$ ) 
Table 2. Summary of device comparisons during a simulated difficult airway.

\begin{tabular}{|c|c|c|c|c|c|}
\hline Characteristic & $\begin{array}{l}\text { Maclntosh Laryn- } \\
\text { goscope } \\
n=25\end{array}$ & $\begin{array}{l}\text { M c G R A T H }{ }^{\circledR} \\
\text { Series } 5 \text { Video } \\
\text { Laryngoscope } \\
n=25\end{array}$ & $\begin{array}{l}\text { Glide Scope }{ }^{\circledR} \\
\text { Video Laryngos- } \\
\text { cope } \\
\mathrm{n}=25\end{array}$ & $\begin{array}{l}\text { Pentax AWS- } \\
\text { S100 Video } \\
\text { Laryngoscope } \\
n=25\end{array}$ & $\begin{array}{l}\text { Fiberoptic Bron- } \\
\text { choscope } \\
n=25\end{array}$ \\
\hline \multicolumn{6}{|l|}{ Ability to assemble the devi- } \\
\hline ce & 23 & 24 & 24 & 18 & 18 \\
\hline Outstanding & 2 & 1 & 1 & 7 & 7 \\
\hline Good & 0 & 0 & 0 & 0 & 0 \\
\hline \multicolumn{6}{|l|}{ Poor } \\
\hline Ability to obtain glottic view & 8 & 19 & 22 & 21 & 8 \\
\hline Outstanding & 14 & 6 & 3 & 4 & 10 \\
\hline Good & 3 & 0 & 0 & 0 & 7 \\
\hline \multicolumn{6}{|l|}{ Poor } \\
\hline \multicolumn{6}{|l|}{ Ability to intubate the tra- } \\
\hline chea & 13 & 16 & 20 & 24 & 2 \\
\hline Outstanding & 9 & 8 & 4 & 1 & 7 \\
\hline Good & 3 & 1 & 1 & 0 & 16 \\
\hline \multicolumn{6}{|l|}{ Poor } \\
\hline \multicolumn{6}{|l|}{ Severity of dental compre- } \\
\hline ssion & 0 & 0 & 1 & 0 & 25 \\
\hline None & 1 & 6 & 9 & 9 & 0 \\
\hline Moderate & 24 & 19 & 15 & 16 & 0 \\
\hline \multicolumn{6}{|l|}{ Severe } \\
\hline Best glottic view & 2 & 15 & 13 & 13 & 18 \\
\hline 1 & 5 & 9 & 11 & 12 & 2 \\
\hline 2 & 13 & 1 & 1 & 0 & 0 \\
\hline 3 & 3 & 0 & 0 & 0 & 0 \\
\hline 4 & 2 & 0 & 0 & 0 & 5 \\
\hline \multicolumn{6}{|l|}{ Glottis not visualized } \\
\hline \multicolumn{6}{|l|}{ Attempts to obtain best } \\
\hline glottic view & 14 & 22 & 23 & 22 & 10 \\
\hline 1 & 8 & 3 & 1 & 3 & 7 \\
\hline 2 & 3 & 0 & 1 & 0 & 8 \\
\hline \multicolumn{6}{|l|}{$3+$} \\
\hline $\begin{array}{l}\text { Median time (sec) to assem- } \\
\text { ble the device and obtain } \\
\text { best glottic view }\left(25^{\text {th }}, 75^{\text {th }}\right)\end{array}$ & $30(22,52)$ & $25(19,38)$ & $23(16,32)$ & $38(32,56)$ & $101(54,152)$ \\
\hline $\begin{array}{l}\text { Success of tracheal intuba- } \\
\text { tion }\end{array}$ & 23 & 25 & 25 & 25 & 9 \\
\hline $\begin{array}{l}\text { Median time to assemble the } \\
\text { device and intubate the tra- } \\
\text { chea* }\left(25^{\text {th }}, 75^{\text {th }}\right)\end{array}$ & $34(26,57)$ & $53(43,74)$ & $38(29,70)$ & $43(37,64)$ & $104(80,159)$ \\
\hline
\end{tabular}

* Median time based on subjects that attempted tracheal intubation (Macintosh $=23$, Fiberoptic $=9$ ) 
Table 3. Summary of differences between devices for normal and difficult airway scenarios.

\begin{tabular}{|c|c|c|c|c|}
\hline Characteristic & Normal Airway & & Difficult Airway & \\
\hline Ability to assemble & Pentax & $<$ all & No difference & \\
\hline \multirow{2}{*}{ Ability to obtain glottic view } & Macintosh & $\begin{array}{l}<\text { GlideScope } \\
<\text { McGRATH } \\
<\text { Pentax }\end{array}$ & Macintosh & $\begin{array}{l}<\text { GlideScope } \\
<\text { McGRATH } \\
<\text { Pentax }\end{array}$ \\
\hline & $\begin{array}{l}\text { Fiberoptic Bronchos- } \\
\text { cope }\end{array}$ & $\begin{array}{l}<\text { GlideScope } \\
<\text { McGRATH } \\
<\text { Pentax }\end{array}$ & $\begin{array}{l}\text { Fiberoptic Bron- } \\
\text { choscope }\end{array}$ & $\begin{array}{l}<\text { GlideScope } \\
<\text { McGRATH } \\
<\text { Pentax }\end{array}$ \\
\hline \multirow[t]{2}{*}{ Ability to intubate } & $\begin{array}{l}\text { Fiberoptic Bronchos- } \\
\text { cope }\end{array}$ & $<$ all & $\begin{array}{l}\text { Fiberoptic Bron- } \\
\text { choscope }\end{array}$ & $<$ all \\
\hline & Pentax & $\begin{array}{l}>\text { GlideScope } \\
>\text { Macintosh }\end{array}$ & Pentax & $>$ Macintosh \\
\hline Dental compression & $\begin{array}{l}\text { Fiberoptic Bronchos- } \\
\text { cope }\end{array}$ & $<$ all & $\begin{array}{l}\text { Fiberoptic Bron- } \\
\text { choscope }\end{array}$ & $<$ all \\
\hline \multirow[b]{2}{*}{ Best glottic view } & \multirow[b]{2}{*}{ Macintosh } & \multirow[b]{2}{*}{$<$ all } & Macintosh & $\begin{array}{l}<\text { GlideScope } \\
<\text { McGRATH }\end{array}$ \\
\hline & & & $\begin{array}{l}\text { Fiberoptic Bron- } \\
\text { choscope }\end{array}$ & $>$ all \\
\hline Number of attempts for best view & $\begin{array}{l}\text { Fiberoptic Bronchos- } \\
\text { cope }\end{array}$ & $\begin{array}{l}>\text { GlideScope } \\
>\text { McGRATH } \\
>\text { Pentax }\end{array}$ & No difference & \\
\hline \multirow{2}{*}{$\begin{array}{l}\text { Time to assemble and get glottic } \\
\text { view }\end{array}$} & $\begin{array}{l}\text { Fiberoptic Bronchos- } \\
\text { cope }\end{array}$ & $>$ all & $\begin{array}{l}\text { Fiberoptic Bron- } \\
\text { choscope }\end{array}$ & \\
\hline & Pentax & $\begin{array}{l}\text { > GlideScope } \\
\text { > McGRATH }\end{array}$ & Pentax & $\begin{array}{l}\text { > GlideScope } \\
>\text { McGRATH }\end{array}$ \\
\hline Success of tracheal intubation & $\begin{array}{l}\text { Fiberoptic Bronchos- } \\
\text { cope }\end{array}$ & $<$ all & $\begin{array}{l}\text { Fiberoptic Bron- } \\
\text { choscope }\end{array}$ & $<$ all \\
\hline Time to assemble and intubate & $\begin{array}{l}\text { Fiberoptic Bronchos- } \\
\text { cope } \\
\text { Pentax }\end{array}$ & $\begin{array}{l}>\text { all } \\
>\text { GlideScope } \\
>\text { McGRATH }\end{array}$ & $\begin{array}{l}\text { Fiberoptic Bron- } \\
\text { choscope }\end{array}$ & $>$ all \\
\hline
\end{tabular}

* All presented comparisons meet statistical significance $(p \leq 0.005)$ after the Bonferroni Correction. 
Table 4. Post-evaluation survey summary.

\begin{tabular}{llllll}
\hline & $\begin{array}{l}\text { Macintosh } \\
\text { Laryngoscope }\end{array}$ & $\begin{array}{l}\text { McGRATH }{ }^{\circledR} \text { Video } \\
\text { Laryngoscope }\end{array}$ & $\begin{array}{l}\text { GlideScope }{ }^{\circledR} \\
\text { Video Laryng- } \\
\text { scope }\end{array}$ & $\begin{array}{l}\text { Pentax } \\
\text { AWS-S100 } \\
\text { Laryngoscope }\end{array}$ & $\begin{array}{l}\text { Fiberoptic Broncho- } \\
\text { scope }\end{array}$ \\
\hline Easiest to set up & $11(44 \%)$ & $7(28 \%)$ & $6(24 \%)$ & 0 & $1(4 \%)$ \\
\hline $\begin{array}{l}\text { Most difficult to } \\
\text { set up }\end{array}$ & $1(4 \%)$ & $1(4 \%)$ & $2(8 \%)$ & $14(56 \%)$ & $7(28 \%)$ \\
\hline $\begin{array}{l}\text { Easiest to use } \\
\text { Most difficult to use }\end{array}$ & $2(8 \%)$ & 0 & $5(20 \%)$ & $8(32 \%)$ & 0 \\
\hline $\begin{array}{l}\text { Choose for normal } \\
\text { airway }\end{array}$ & $5(20 \%)$ & $9(36 \%)$ & $1(4 \%)$ & 0 & $22(88 \%)$ \\
\hline $\begin{array}{l}\text { Choose for difficult } \\
\text { airway }\end{array}$ & 0 & $8(32 \%)$ & $3(12 \%)$ & $8(32 \%)$ & 0 \\
\hline
\end{tabular}

\section{APPENDIX 1.}

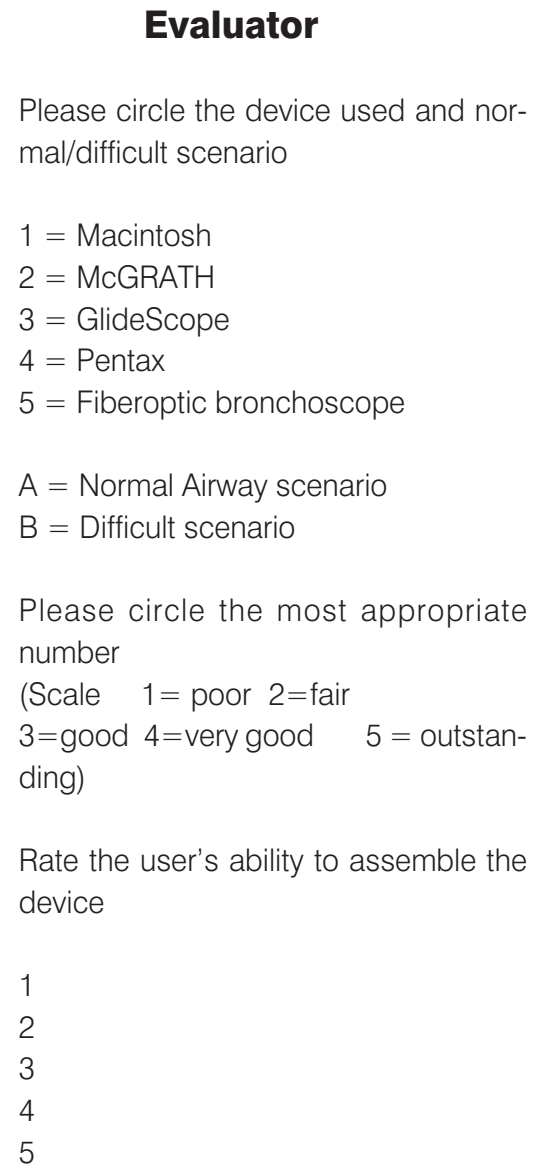

Rate the user's ability to obtain view of the glottis using the device

1
2
3
4
5

Rate the user's ability to pass an endotracheal tube into the trachea using the device

1
2
3
4
5

Rate the severity of dental compression:

None scope blade not touching the mannequin's teeth)

Moderate (scope blade touching the mannequin's teeth)

Severe (touching and deforming the mannequin's teeth)
Best Mallampati Grade view seen (see guide below)

3- 2 -

Number of attempts required to obtain "best" Mallampati Grade glottic view

Time required to successfully assemble the device plus obtain "best" Mallampati Grade glottic view : seconds

Trachea successfully intubated

$$
\text { Yes_ No }
$$

Number of attempts required to successfully intubate the trachea

Time required to successfully assemble the device plus intubate the trachea (Max time for exercise is $180 \mathrm{~s}$ ) seconds

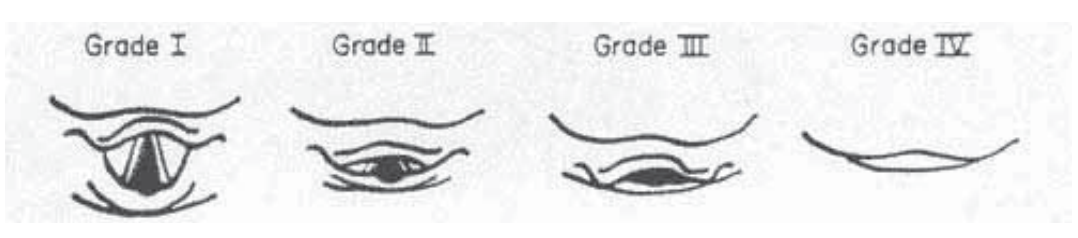




\section{APPENDIX 2}

\section{Post Evaluation Survey}

1. Which device was the easiest to set-up?

1. Macintosh blade

2. McGRATH laryngoscope

3. GlideScope

4. Pentax laryngoscope

5. Fiberoptic bronchoscope

2. Which device was the most difficult to set-up?

1. Macintosh blade

2. McGRATH laryngoscope

3. GlideScope

4. Pentax laryngoscope

\section{Fiberoptic bronchoscope}

3. Overall, which device was the easiest to use?

1. Macintosh blade

2. McGRATH laryngoscope

3. GlideScope

4. Pentax laryngoscope

5. Fiberoptic bronchoscope

4. Overall, which device was the most difficult to use?

1. Macintosh blade

2. McGRATH laryngoscope

3. GlideScope

4. Pentax laryngoscope

5. Fiberoptic bronchoscope
5. Which device would you choose to intubate the trachea of a patient with a 'normal' appearing airway?

1. Macintosh blade

2. McGRATH laryngoscope

3. GlideScope

4. Pentax laryngoscope

5. Fiberoptic bronchoscope

6. Which device would you choose to intubate the trachea of a patient with a 'difficult' appearing airway?

1. Macintosh blade

2. McGRATH laryngoscope

3. GlideScope

4. Pentax laryngoscope

5. Fiberoptic bronchoscope

\section{ACKNOWLEDGMENTS}

We express deep gratitude to Paul Warner (First Year medical student, Mayo Clinic College of Medicine), the equipment representatives (Genevieve Chase of GlideScope, Jesse Kuechle of McGRATH, Steve Oborsky of Olympus, and Gene Eldridge of Pentax), Mayo Clinic Multidisciplinary Simulation Center staff for helping us bring this study to fruition.

\section{REFERENCES}

1. Nouruzi-Sedeh P, Schumann M, Groeben H. Laryngoscopy via Macintosh blade versus GlideScope: success rate and time for endotracheal intubation in untrained medical personnel. Anesthesiology 2009;110:32-7.

2. Timmermann A, Russo SG, Crozier TA, Eich C, Mundt B, Albrecht B, et al. Novices ventilate and intubate quicker and safer via intubating laryngeal mask than by conventional bag-mask ventilation and laryngoscopy. Anesthesiology 2007;107:570-6.

3. Konrad C, Schupfer G, Wietlisbach M, Gerber H. Learning manual skills in anesthesiology: Is there a recommended number of cases for anesthetic procedures? Anesth Analg 1998;86:635-9

4. Mulcaster JT, Mills J, Hung OR, MacQuarrie K, Law A, Pytka S, et al. Laryngoscopic intubation: learning and performance. Anesthesiology 2003:98:23-7

5. Cormack RS, Lehane J. Difficult tracheal intubation in obstetrics. Anaesthesia 1984;39:1105-11.

6. Mallampati SR, Gatt SP, Gugino LD, Desai SP, Waraksa B, Freiberger D, et al. A clinical sign to predict difficult tracheal intubation: a prospective study. Can Anaesth Soc J 1985;32:429-34.

7. Flores AS, Garber SM, Niesen AD, Long TR, Lynch JJ, Wass CT. Clinical application of a novel video camera laryngoscope: a case series venturing beyond the normal airway. J Clin Anesth 2010;22:201-4.

8. Narang AT, Oldeg PF, Medzon R, Mahmood AR, Spector JA, Robinett DA. Comparison of intubation success of video laryngoscopy versus direct laryngoscopy in the difficult airway using high-fidelity simulation. Simul Healthc 2009;4:160-5.

9. O'Leary AM, Sandison MR, Myneni N, Cirilla DJ, Roberts KW, Deane GD. Preliminary evaluation of a novel videolaryngoscope, the McGrath series 5, in the management of difficult and challenging endotracheal intubation. J Clin Anesth 2008;20:320-1.

10. Shippey B, Ray D, McKeown D. Case series: the McGrath videolaryngoscope--an initial clinical evaluation. Can J Anaesth 2007;54:307-13.

11. Practice guidelines for management of the difficult airway: an updated report by the American Society of Anesthesiologists Task Force on Management of the Difficult Airway. Anesthesiology 2003;98:1269-77.

12. Connelly NR, Ghandour K, Robbins L, Dunn S, Gibson C. Management of unexpected difficult airway at a teaching institution over a 7-year period. J Clin Anesth 2006;18:198-204. 